\title{
Formation and Phase Transitions of Hydrated Vanadium Oxides with Layered Structures
}

\author{
Yoshio OKA, Naoichi YAMAMOTO, Tsukio OHTANI* and Toshio TAKADA* \\ ( Department of Chemistry, College of Liberal Arts and Sciences, Kyoto University, Sakyo-ku, Kyoto-shi 606 ) \\ * Department of Chemistry, Faculty of Science, Okayama University of Science, Ridai-cho, Okayama-shi 700$)$
}

\section{層状構造をもつ水和バナジウム酸化物の合成と相転移}

\author{
岡 与志男・山本 直一・大谷梘男*・高田利夫* \\ ( 京都大学教養部化学教室, 606 京都市左京区吉田二本松町 $)$ \\ * 岡山理科大学理学部化学教室, 700 岡山市理大町
}

\begin{abstract}
Hydrated vanadium oxides were prepared by hydrothermal treatment of aqueous $\mathrm{VOSO}_{4}$ solutions. The products were found to take layered structures based on the $V_{2} O_{5}$ structure. Phases with the layer spacings of 7.1, 8. 3, 13.2, 14.2 and $19.0 \AA$ were obtained and a primary product was the phase with the spacing of $14.2 \AA$ (phase $I$ ). The composition of the phase $I$ was estimated as $\mathrm{V}_{2} \mathrm{O}_{5-\sigma^{\circ}} n \mathrm{H}_{2} \mathrm{O}(0<\delta<0.2,1.5<n<2.5)$. An additional phase with the spacing of $17.3 \AA$ (phase $I^{\prime}$ ) was found in as-filtrated samples, which changed to the phase I by drying. The phase I transformed succesively into the phases with smaller layer spacings by dehydration on heating or evacuating. The overall transitions were as follows ; $I^{\prime}$ $(17.3 \AA) \rightarrow I(14.2 \AA) \rightarrow I \alpha^{\prime}(12.6 \AA) \rightarrow I \alpha(11.5 \AA) \rightarrow I \beta(10.0 \AA) \rightarrow I \gamma(8.3 \AA)$. The transition from phase $I$ to $I \beta$ was reversible. These layer-type phases were distinguished from $\mathrm{V}_{2} \mathrm{O}_{5}$ gels.
\end{abstract}

[Received June 9, 1989 ; Accepted September 18, 1989]

Key-words : Vanadium oxides, Hydrothermal synthesis, Hydrates, Layered structure, Intercalation, Phase transition

\section{Introduction}

Layered structures have received much attention for the two-dimensional properties and intercalation phenomena as well as practical uses as catalysts and ion exchangers. The structure of $\mathrm{V}_{2} \mathrm{O}_{5}$ is regarded as a layer type and the incorporation of water molecules between the $\mathrm{V}_{2} \mathrm{O}_{5}$ layers leads to $\mathrm{V}_{2} \mathrm{O}_{5}$ gels. Thus $\mathrm{V}_{2} \mathrm{O}_{5}$ gels are of highly two-dimensional nature. $\mathrm{V}_{2} \mathrm{O}_{5}$ gels have been prepared by several methods such as polymerization of polyvanadic acid, ${ }^{1)}$ gelation of vanadyl triethoxide ${ }^{2)}$ and quenching of molten $\mathrm{V}_{2} \mathrm{O}_{5}$ in water. ${ }^{3)} \mathrm{V}_{2} \mathrm{O}_{5}$ gels are represented by the formula $\mathrm{V}_{2} \mathrm{O}_{5} \cdot n \mathrm{H}_{2} \mathrm{O}$ with $0<n<20 .{ }^{4)} \mathrm{V}_{2} \mathrm{O}_{5}$ xeogel obtained by dehydration of hydrogels at $\mathrm{RT}$ has a formula of $\mathrm{V}_{2} \mathrm{O}_{5} \cdot 1.6 \mathrm{H}_{2} \mathrm{O}$ with the layer spacing of $11.55 \AA$ which changes to $\mathrm{V}_{2} \mathrm{O}_{5} \cdot 0.5 \mathrm{H}_{2} \mathrm{O}$ with that of $8.75 \AA$ above $100^{\circ} \mathrm{C}$ in air. ${ }^{5)}$ The contraction of the layer spacing by $2.8 \AA$ has been attributed to the removal of monolayer of water molecules. ${ }^{5)}$ The oxidation number of vanadium in $\mathrm{V}_{2} \mathrm{O}_{5}$ gels is usually less than five, reaching to 4.9 for meltquenched $\mathrm{V}_{2} \mathrm{O}_{5}$ gel ${ }^{6,7)}$ and the presence of $\mathrm{V}^{4+}$ ions has been reported to play an important role on the formation of the gels as well as the electrical properties. ${ }^{6)-9)}$

It is of interest to prepare crystalline phases with layered structures analogous to $\mathrm{V}_{2} \mathrm{O}_{5}$ gels under hydrothermal conditions. In the present study, phases with layered structures were obtained by hydrothermal treatment of aqueous $\mathrm{VOSO}_{4}$ solutions. The conditions of preparing phases with different layer spacings were examined and phase transitions induced by the dehydration and also by the subsequent hydration were observed.

\section{Experimental}

Hydrothermal treatment was conducted as follows. Aqueous $\mathrm{VOSO}_{4}$ solutions with the concentrations of $4 \times 10^{-4}$ to $4 \times 10^{-2} \mathrm{M}$ were sealed in pyrex tubes and were treated in a Morey-type autoclave at $110^{\circ}$ to $280^{\circ} \mathrm{C}$ for 10 to $60 \mathrm{~h}$. Precipitates were separated by filtration and dried in air. An average oxidation number of vanadium in the precipitate was determined by the absorptiometry on a sample dissolved in a sulfuric acid solution. Water content was obtained from a weight loss of dehydration by heating in air up to $400^{\circ} \mathrm{C}$. Crystalline phases were examined by the $\mathrm{X}$-ray diffraction method using $\mathrm{Cu} K \alpha$ radiation. Hightemperature X-ray measurements were carried out using a JEOL high-temperature attachment to controll temperature within $\pm 1^{\circ} \mathrm{C}$. 


\section{Results and discussion}

Figure 1 shows X-ray diffraction patterns of the air-dried products taken in the reflection mode, in which appeared exclusively a series of $00 \ell$ peaks indicating that the phases are strongly of layer type. As seen in Fig. 1, there are phases with the layer spacings of $14.2,8.3,19.0,7.1$ and $13.2 \AA$ designated as phase I, II, III, IV and V, respectively. Formation of these phases were found to be governed by $\mathrm{VOSO}_{4}$ concentrations and reaction temperatures. Figure 2 shows a formation diagram with the parameters of $\mathrm{VOSO}_{4}$ concentration and reaction temperature for a reaction time of $24 \mathrm{~h}$. In the present hydrothermal system, the average oxidation numbers of $\mathrm{V}$ in the products lie between four and five depending on both $\mathrm{VOSO}_{4}$ concentrations and reaction temperatures. ${ }^{10)}$ That is, they become lower for higher $\mathrm{VOSO}_{4}$ concentrations or for higher reaction temperatures and vice versa. In a fairly low concentration range of less than $20 \mathrm{mM}$, the oxidation numbers of $\mathrm{V}$ strongly depend on $\mathrm{VOSO}_{4}$ concentrations rather than reaction temperatures being greater than 4. 6. ${ }^{10)}$ Therefore, hydrated vanadium oxides based on $\mathrm{V}_{2} \mathrm{O}_{5}$ are expected to be formed under the conditions of Fig. 2 and $\mathrm{V}_{3} \mathrm{O}_{7} \cdot \mathrm{H}_{2} \mathrm{O}$ for the higher $\mathrm{VOSO}_{4}$ concentrations. As for the degrees of hydration, lower hydrated phases are generally obtained for higher reaction temperatures and thus $\mathrm{V}_{2} \mathrm{O}_{5}$ was precipitated above $250^{\circ} \mathrm{C}$. Moreover, as will be described later, the phase II , which was regarded as lower hydrated phase of the phase I, was formed at reaction temperatures higher than the phase I. As seen in Fig. 2, the phase I was obtained as single phase in a wide range of the diagram. The phases III and IV were obtained in an extremely low concentration range of less than $5 \mathrm{mM}$ and hence it was unsuccessful to have an amount enough for further study. The phases II and $\mathrm{V}$ were usually obtained with other phases and were difficult to be separated. Therefore, the present study has been focused on the phase I. It is noticed that the effect of $\mathrm{SO}_{4}^{2-}$ ion, which is considered to be a major impurity ion in this system, on the formation of the layer-type phases, should be ruled out because these layertype phases were also obtained in hydrothermal treatment of $\mathrm{VO}(\mathrm{OH})_{2}$ free from $\mathrm{SO}_{4}^{2-}$ ion. ${ }^{11)}$ The morphology of the phase I is of flat plates as seen in Fig. 3 reflecting the two-dimensional feature. The composition of the phase I was estimated as $\mathrm{V}_{2} \mathrm{O}_{5-\sigma} \cdot n \mathrm{H}_{2} \mathrm{O}$ where $0<\delta<0.2$ and $1.5<n<2.5$ depending on preparation conditions. As shown in Fig. 4, an additional layer-type phase with the spacing of $17.3 \AA$ designated as phase $I^{\prime}$ was

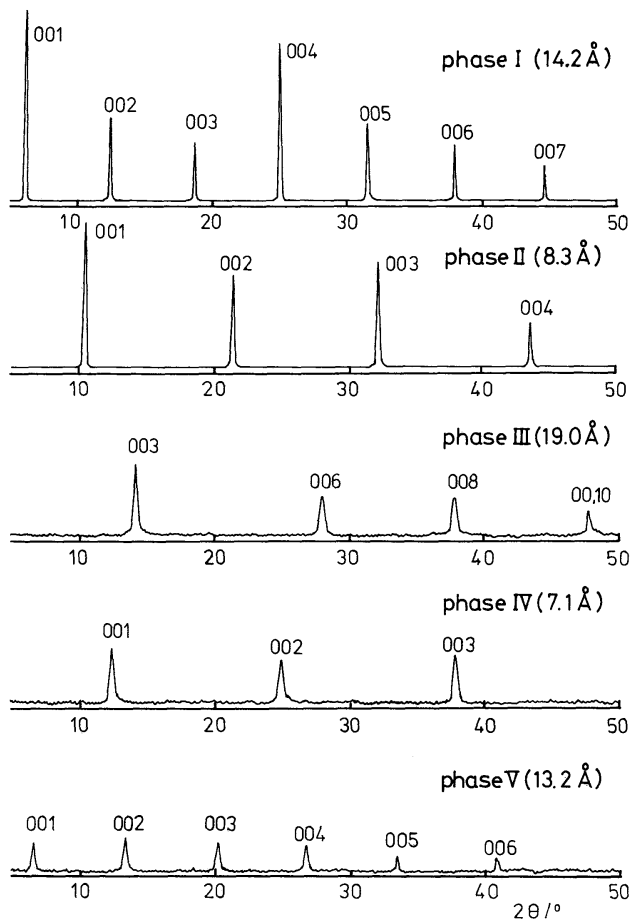

Fig. 1. X-ray diffraction patterns of the phase $\mathrm{I}$ to $\mathrm{V}$ for air-dried products.

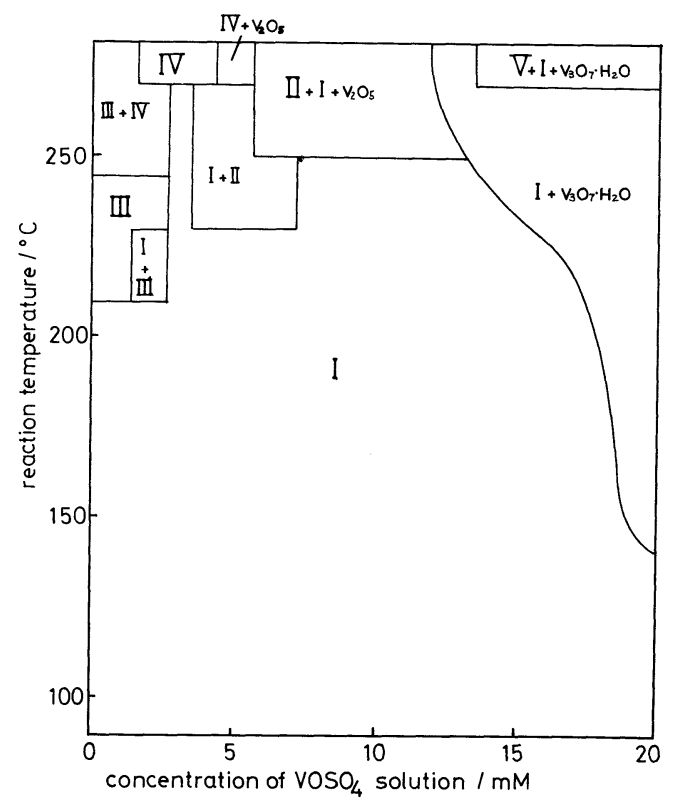

Fig. 2. Formation diagram of the hydrothermal synthesis of the phase $\mathrm{I}$ to $\mathrm{V}$ with the parameters of concentration of $\mathrm{VOSO}_{4}$ solution and reaction temperature for reaction time of $24 \mathrm{~h}$.

found in as-filtrated and wet samples synthesized below $240^{\circ} \mathrm{C}$. Figure 4 shows that as-filtrared samples synthesized at $170^{\circ}, 240^{\circ}$ and $260^{\circ} \mathrm{C}$ 
adopted the phase $I^{\prime}$, the phase $I^{\prime}+I$ and the phase $\mathrm{I}$, respectively, which were all changed into the phase I by drying. Therefore the phase $I^{\prime}$ is a higher hydrated form of the phase $I$. In order to examine the intralayer structure of the phase I, an X-ray diffraction pattern was taken in the transmission mode as shown in Fig. 5. As seen in Fig. 5, the X-ray peaks in the transmission mode well correspond to those of $\mathrm{V}_{2} \mathrm{O}_{5}$ with $h 0 \ell$ reflections. It indicates that the intralayer structure of the phase $\mathrm{I}$ is closely related to the $\mathrm{V}_{2} \mathrm{O}_{5}$ structure.

Phase transitions of the phase $I$ induced by dehydration on heating in air were investigated by the high-temperature X-ray measurements as shown in Fig. 6. It was found that the phase I was changed succesively into the phases with the layer spacings of $11.5,10.0$ and $8.3 \AA$ designated as phase $\mathrm{I} \alpha, \mathrm{I} \beta$ and $\mathrm{I} \gamma$, respectively; $\mathrm{I} \stackrel{\sim 67^{\circ} \mathrm{C}}{\longrightarrow}$ $\mathrm{I} \alpha \stackrel{\sim 92^{\circ} \mathrm{C}}{\longrightarrow} \mathrm{I} \beta \stackrel{350^{\circ}-430^{\circ} \mathrm{C}}{\longrightarrow} \mathrm{I} \gamma$. Further heating above $520^{\circ} \mathrm{C}$ yielded $\mathrm{V}_{2} \mathrm{O}_{5}$. It is noteworthy that the transition from the phase I to the phase $I \beta$ was reversible, i. e., the phase I $\beta$ returned to the phase I on hydration while the phase $I \gamma$ was

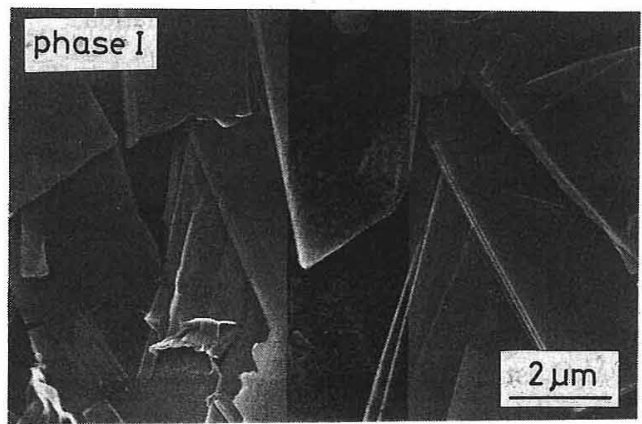

Fig. 3. SEM photograph of the phase I.

Synthesized at $170^{\circ} \mathrm{C}$

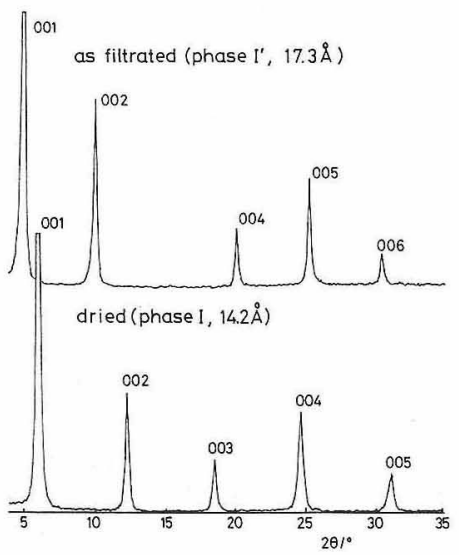

unchanged. Judging from the layer spacings and the X-ray diffraction profiles, the phase I $\gamma$ seems to be the same as the phase II. So the phase II is regarded as a lower hydrated form of the phase I as mentioned above. The phase $\mathrm{I} \alpha$ exhibits a resemblance to $\mathrm{V}_{2} \mathrm{O}_{5}$ xerogel $\left(\mathrm{V}_{2} \mathrm{O}_{5} \cdot 1.6 \mathrm{H}_{2} \mathrm{O}\right)$ with respect to the layer spacing and the apparent lack

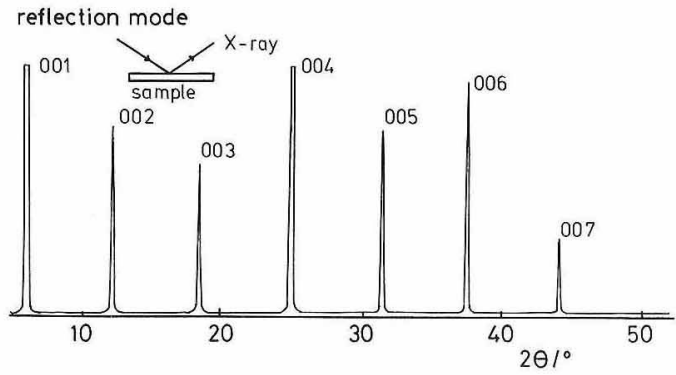

transmission mode

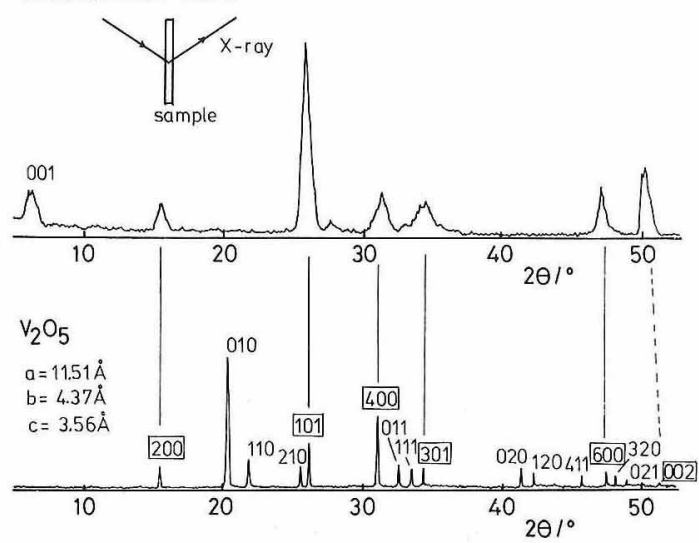

Fig. 5. X-ray diffraction patterns of the phase I taken in the reflection mode (top) and transmission mode (bottom) together with that of $\mathrm{V}_{2} \mathrm{O}_{5}$ for comparison.
Synthesized at $260^{\circ} \mathrm{C}$

(c)

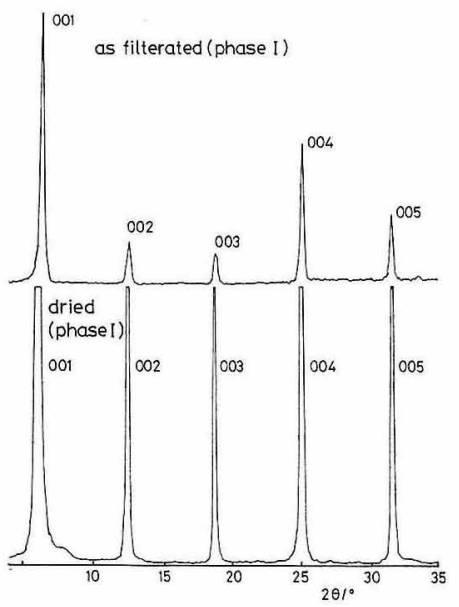

Fig. 4. X-ray diffraction patterns of the products for as-filtrated and air-dried samples synthesized at $170^{\circ}(\mathrm{a})$, $240^{\circ}$ (b) and $260^{\circ} \mathrm{C}(\mathrm{c})$. 


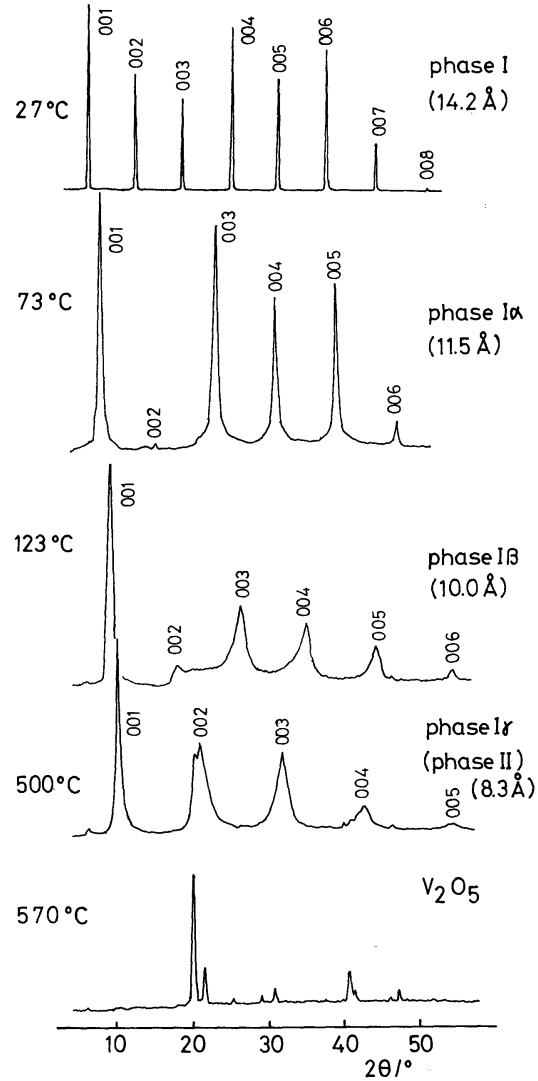

Fig. 6. High-temperature X-ray diffraction patterns of the phase I taken in air.

of 002 reflection. ${ }^{5)}$ But it has been reported ${ }^{5}$ that $\mathrm{V}_{2} \mathrm{O}_{5} \cdot 1.6 \mathrm{H}_{2} \mathrm{O}$ was changed to $\mathrm{V}_{2} \mathrm{O}_{5} \cdot 0.5 \mathrm{H}_{2} \mathrm{O}$ with the spacing of $8.75 \AA$ above $100^{\circ} \mathrm{C}$ being different from the present case, hence it is doubtfull that the phase $\mathrm{I} \alpha$ is the same as the $\mathrm{V}_{2} \mathrm{O}_{5}$ xerogel. From the weight loss on heating, $n$ in $\mathrm{V}_{2} \mathrm{O}_{5-\sigma} \cdot n \mathrm{H}_{2} \mathrm{O}$ was estimated to be $0.5-1.0$ for the phase I $\alpha, 0.1-0.5$ for the phase I $\beta$ and 0.1 for the phase I $\gamma$. Phase transitions of the phase I induced by dehydration were also observed in evacuation at $14^{\circ} \mathrm{C}$ as shown in Fig. 7. In this case, a new phase with the spacing of $12.6 \AA$ was detected as an intermediate phase in a narrow range between the phase $\mathrm{I}$ and $\mathrm{I} \alpha$, which was designated as phase $\mathrm{I} \alpha^{\prime}$. The phase $\mathrm{I} \alpha^{\prime}$ was not observable in evacuation above $20^{\circ} \mathrm{C}$. To sum up, the phase $\mathrm{I}$ was changed to the phase $\mathrm{I} \beta$ through the phase $\mathrm{I} \alpha^{\prime}$ and $\mathrm{I} \alpha$ by dehydration at $14^{\circ} \mathrm{C}$ and the transition was reversible. It is noted in Fig. 7 that the trace of 001 reflection of the phase I seen in (c) to (f) may be due to the phase I remaining in the portion of the sample sheet adhered to the sample holder which seemed hard to dehydrate. The weight loss by evacuation at $14^{\circ} \mathrm{C}$ as a

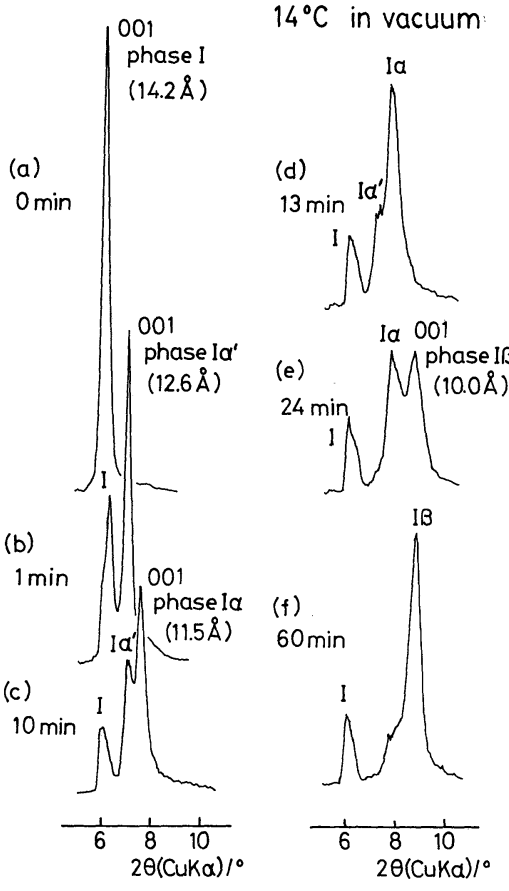

Fig. 7. X-ray diffraction patterns of the phase I taken in vacuum at $14^{\circ} \mathrm{C}$ for time after evacuation.

function of time is shown in Fig. 8. The weight loss curve shows a slight deflection around $3 \mathrm{~h}$ after evacuation in the region of phase $I \beta$. At present the origin of the deflection remains nuclear.

In conclusion, various phases of hydrated vanadium oxides with layered structure based on the $\mathrm{V}_{2} \mathrm{O}_{5}$ structure were formed under hydrothermal conditions. The phase I with the spacing of 14. $2 \AA$ was obtained as a primary product and also the phase $I^{\prime}$ with the spacing of $17.3 \AA$ was found as a higher hydrated phase of the phase I. There were, in total, succesive transitions induced by dehydration ; phase $I^{\prime}(17.3 \AA) \rightarrow$ phase I (14.2 $\AA) \rightarrow$ phase $\mathrm{I} \alpha^{\prime}(12.5 \AA) \rightarrow$ phase $\mathrm{I} \alpha(11.5 \AA) \rightarrow$ phase $\mathrm{I} \beta(10.0 \AA) \rightarrow$ phase $\mathrm{I} \gamma(8.3 \AA)$. The transitions from phase I to $\mathrm{I} \beta$ were reversible for dehydration and hydration cycles. In contrast to $\mathrm{V}_{2} \mathrm{O}_{5}$ gels, the layer-type phases in the present study showed a variety of layer spacings sensitive to the degree of hydration which was rather lower than that of $\mathrm{V}_{2} \mathrm{O}_{5}$ gels. The layer-type phases gave X-ray peaks much sharper than those of $\mathrm{V}_{2} \mathrm{O}_{5}$ gels indicating that the layer-type phases adopt more regular crystalline structures. In practice, the phases with the spacings similar to those of the present layer-type phases were reported in $\mathrm{V}_{2} \mathrm{O}_{5}$ gels $^{4)}$; the spacings of 14.4 and $18.7 \AA$ may correspond to those of phase I and III, respec- 


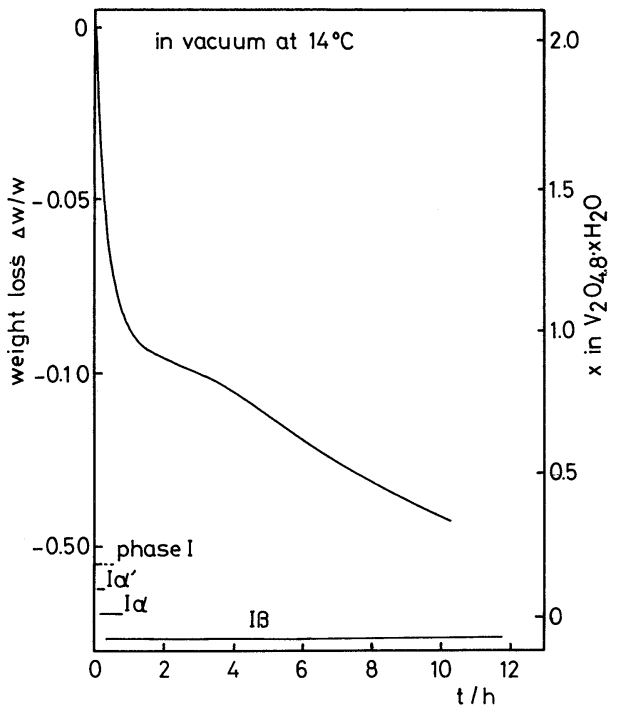

Fig. 8. Weight loss of the phase I taken in vacuum at $14^{\circ} \mathrm{C}$ as a function of time after evacuation.

tively. However, these phases of $\mathrm{V}_{2} \mathrm{O}_{5}$ gels are not identical with phase I or III from the follow: ing reasons. According to Ref. 4), the phase with the spacing of $14.4 \AA$ gave six X-ray peaks of $00 l$ reflections in the $2 \theta$ range of $2^{\circ}$ to $50^{\circ}$, whereas phase $I$ gives seven peaks in the same $2 \theta$ range as shown in Fig. 1. Next, the phase with the spacing of $18.7 \AA$ gave 001 and 002 reflections, ${ }^{4)}$ whereas these peaks are missing in phase III as shown in Fig. 1. Therefore, there is no phase in the present study which coincides with that of $\mathrm{V}_{2} \mathrm{O}_{5}$ gels. Moreover, the behavior of phase transitions induced by dehydration in the layer- type phases was found to be more complicated than that of the $\mathrm{V}_{2} \mathrm{O}_{5}$ xerogels. ${ }^{5)}$ Consequently, the layer-type phases should be distinguished from $\mathrm{V}_{2} \mathrm{O}_{5}$ gels. Further study is in progress to elucidate the intralayer structures, the structures of intercalated water molecules for different layer spacings and the role of $\mathrm{V}^{4+}$ ion on stablizing the layered structures.

Acknowledgements The authors are gratefull to Professor K. Kosuge and Dr. Y. Ueda of Kyoto University for their continuing interest and encouragement. Thanks are also due to Professor S. Kittaka of Okayama University of Science for valuable discussions. The present work was partly supported by a Grant-in-Aids for Scientific Research from Ministry of Education, Science and Culture.

\section{References}

1) J. Lemerle, L. Nejem and J. Lefebvre, J. inorg. nucl. Chem., 42, 17-20 (1979).

2) H. Hirashima, K. Tsukimi and R. Muratake, SeramikkuRonbunshi, 97, 235-38 (1989).

3) M. Michaud, M. C. Leroy and J. Livage, Mater. Res. Bull., 11, 1425-32 (1976).

4) P. Aldebert, H. W. Hasslin, N. Baffier and J. Livage, J. Colloid Interface Sci., 98, 478-83 (1984).

5) P. Aldebert, N. Baffier, N. Gharbi and J. Livage, Mater. Res. Bull., 16, 669-76 (1981).

6) J. Bullot, P. Cordier, O. Gallais and M. Gauthier, J. Non-Cryst. Solids, 68, 123-34 (1984).

7) P. Kounavis, A. Vomvas, E. Mytilineou, M. Roilos and L. Murawski, J. Phys. C, 21, 967-73 (1988).

8) N. Gharbi, C. Sanchez, J. Livage, J. Lemerle and J. Lefevre, Inorg. Chem., 21, 2758-65 (1982).

9) C. Sanchez, F. Babonneau and J. Livage, Phil. Mag. $B, 47,279-90$ (1983).

10) Y. Oka and N. Yamamoto, presented at the 54th Spring Meeting of the Chemical Society of Japan, 1987, 2VIB 08.

11) Y. Oka and N. Yamamoto, unpublished work. 